\title{
Os impactos e influências da Revista Brasileira de Ensino de Física
}

\author{
Impacts and influences of the Revista Brasileira de Ensino de Física \\ Peter Alexander Bleinroth Schulz ${ }^{* 10}$ \\ ${ }^{1}$ Universidade Estadual de Campinas, Faculdade de Ciências Aplicadas, Limeira, SP, Brasil
}

Recebido em 02 de Agosto, 2018. Aceito em 03 de Agosto, 2018.

\begin{abstract}
O impacto e a influência da Revista Brasileira de Física são analisados através de citações a artigos publicados na revista coletadas nas bases Web of Science, Scopus e Google Citations. O uso da revista é analisado através de indicadores de acessos, uma métrica complementar que vem ganhando importância na avaliação com base cientométrica, a partir de indicadores do Scielo Analytics.
\end{abstract}

Palavras-chave: periódicos científicos, citações, cientometria, altmetria.

The impact and influence of the Revista Brasileira de Ensino de Física are analyzed through citations to documents published in the journal retrieved from the Web of Science and Scopus databases, as well as, from Google Citations. The journal usage is analyzed by means of accesses counting from Scielo Analytics. Accesses counting is a complementary metric of growing importance in scientometric based evaluations.

Keywords: scientific journals, citatiosn, scientometrics, altmetrics.

\section{Introdução}

A Revista Brasileira de Ensino de Física (RBEF), editada pela Sociedade Brasileira de Física desde 1979, é uma publicação de acesso livre,

"voltada à melhoria do ensino de Física em todos os níveis de escolarização. Através da publicação de artigos de alta qualidade, revisados por pares, a revista busca promover e divulgar a Física e ciências correlatas, contribuindo para a educação científica da sociedade como um todo. Ela publica artigos sobre aspectos teóricos e experimentais de Física, materiais e métodos instrucionais, desenvolvimento de currículo, pesquisa em ensino, história e filosofia da Física, política educacional e outros temas pertinentes e de interesse da comunidade engajada no ensino e pesquisa em Física". (http://www.sbfisica.org.br/rbef/)

Uma análise de seu impacto é possível a partir de indicadores disponíveis nas bases bibliográficas em que a revista está indexada, considerando também os aspectos qualitativos delineados na declaração de sua missão reproduzida acima, quanto ao objetivo (sublinhado) e conteúdo (itálico). A RBEF está indexada na base Scielo desde 2002, bem como nas bases Scopus e Web of Sci-

*Endereço de correspondência: peter.schulz@fca.unicamp.br ence (WoS) a partir de 2006 e 200711 respectivamente. É importante destacar que a simples indexação e permanência em bases bibliográficas revela o cumprimento de exigências de qualidade editorial elevadas.

A medida da influência de um artigo ou revista não se limita, no entanto, ao número de citações em artigos de revistas indexadas em bases como a Scopus e a Web of Science [1]. Essa métrica se restringe apenas a uma parte da comunidade de pares. Embora seja uma medida importante, devemos lembrar que um artigo pode exercer influência/impacto e não ser citado por um autor influenciado. Além disso, a métrica baseada em citações exclui o impacto de um artigo sobre outros atores sociais não voltados exclusivamente à produção científica, mas à aplicação do conhecimento científico em outros grupos, que não as comunidades de pares. Um exemplo é a influência na formação de pessoas: esse impacto pode ser parcialmente capturado por citações em trabalhos de conclusão de curso, dissertações e teses, que é possível pelo Google Acadêmico [2]. No entanto, a influência de um periódico como a RBEF vai além, pois seus artigos tem a função de disseminação do conhecimento entre professores, estudantes (e também o público em geral) e o uso de seu conteúdo em salas de aula e laboratórios no aprimoramento de práticas pedagógicas. Essa influência é não citável, mas mensurável pelos números de acessos aos artigos, indicador de importância crescente na ten-

\footnotetext{
1 A RBEF foi indexada na coleção principal da WoSde 2007 até 2013 A partir desse ano passou a ser possível acessar pela WoS todos os documentos também indexados no Scielo com a incorporação do
} Scielo índex na plataforma da Clarivate. 
dência de métricas alternativas (altmetrics) de impacto científico [3]

\section{Indexação}

Na base Scielo a RBEF está classificada apenas na área de Ciências Humanas, enquanto que na Scopus, tanto em Física e Astronomia, quanto Ciências Sociais; na WoS a indexação por assunto também é dupla: Education, Scientific Disciplines e Physics, Multidiscplinary. Essa classificação é relevante pois indica a percepção das bases em relação ao possível público alvo e do conteúdo da revista. As bases internacionais apresentam, portanto, uma percepção (correta) de que a RBEF tem o potencial de um duplo escopo, o que, de fato, se revela nas citações recebidas em ambas as bases.

\section{Impactos por citações: Scopus, WoS e Google Citations}

\subsection{Scopus}

Os artigos da RBEF indexados na Scopus totalizam 1007 documentos ${ }^{2}$ aferidos em 25 de julho de 2018. O número de citações recebidas totaliza 954, distribuídas em 710 artigos citantes. A Figura 1 ilustra as citações recebidas entre 2014 e 2018. Observa-se claramente a tendência de crescimento, que deve ser corroborado quando o ano de 2018 estiver contabilizado por completo.

Uma visão mais interessante é obtida tomando-se a análise dos artigos citantes, que é em número menor que o total de citações em função de possíveis múltiplas

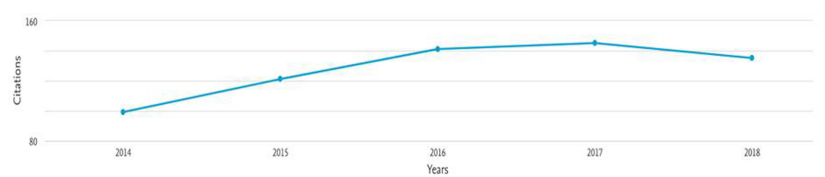

Figura 1: Citações de artigos publicados pela RBEF (Fonte: Scopus, imagem de tela).

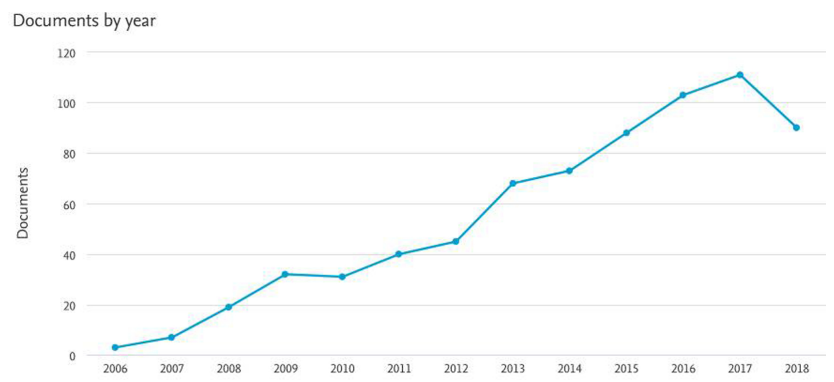

Figura 2: Documentos que citam documentos publicados na RBEF (Fonte: Scopus, imagem de tela).

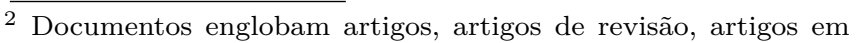
anais de conferências, resenhas e notas.
}

referências à RBEF em uma parcela dos artigos. A Figura 2 mostra a evolução do número de documentos indexados na base Scopus e que citam documentos publicados na RBEF desde 2006.

Os artigos citantes estão distribuídos em um grande número de revistas com predominância da própria RBEF (226 de 710 artigos, 32\%), que é uma tendência normal. A Figura 3 ilustra a evolução temporal para as principais revistas em número de seus artigos que citam o conteúdo da RBEF. Observa-se a presença crescente (embora ainda pequena em números absolutos) de revistas internacionais voltadas à temática de Ensino de Física com artigos que citam a RBEF.

Entre os 710 documentos que citam documentos da RBEF, 447 (63\%) têm coautores de instituições brasileiras, as demais autorias (sem nenhuma instituição brasileira) estão distribuídas conforme o histograma na Figura 4.

Os resultados indicados nas Figuras 3 e 4 sugerem uma crescente, ainda que incipiente, influência internacional da RBEF. Além disso, é possível verificar a que áreas do conhecimento as revistas, que publicaram esses artigos (documentos da RBEF) estão vinculadas. A distribuição desses artigos citantes por área de conhecimento está na Figura 5. Todos os artigos da RBEF estão classificados como de Física e Astronomia e Ciências Sociais, como já mencionado, mas é visível o impacto desses artigos (via suas citações) em outras áreas do conhecimento. As duas áreas de origem somam $62 \%$ do total, sendo seguidas por Engenharia, Matemática, Ciências da Computação,

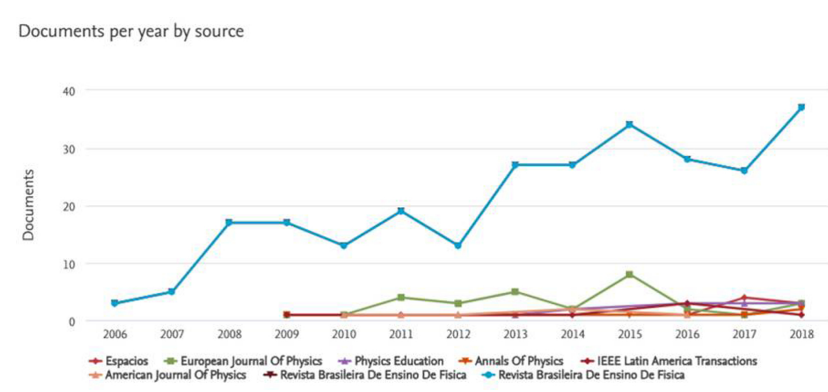

Figura 3: Distribuição dos artigos citantes por revistas, ano a ano (Fonte: Scopus, imagem de tela).

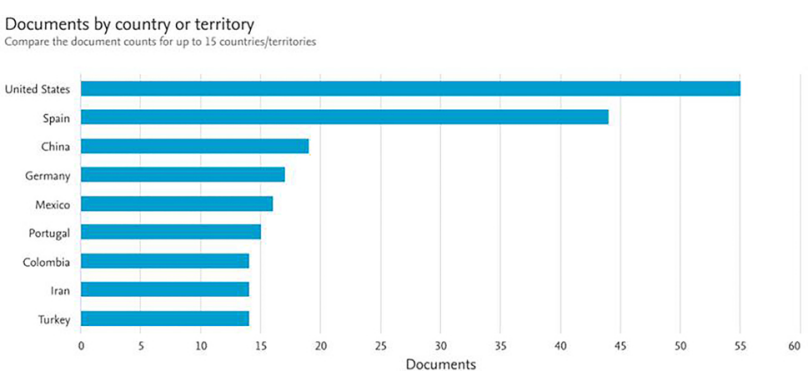

Figura 4: Histograma indicando o número de artigos de outros países (sem participação brasileira) que citam documentos publicados na RBEF (imagem de tela). 
Documents by subject area

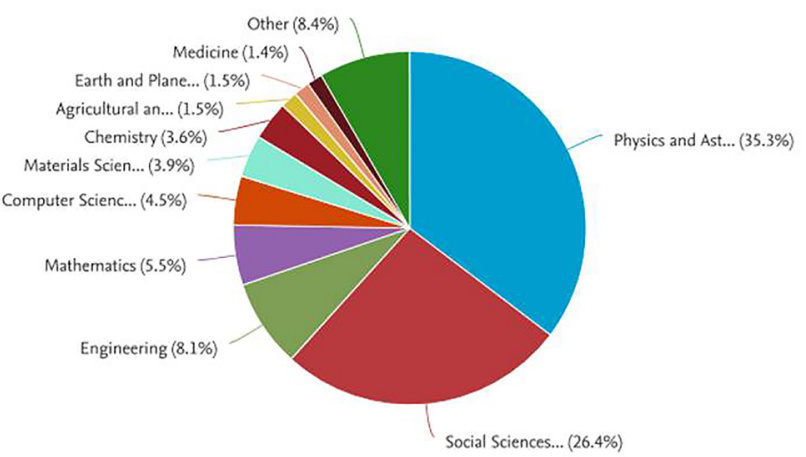

Figura 5: Distribuição dos documentos citantes da RBEF por áreas de conhecimento, segundo a base Scopus (Imagem de tela).

Ciências dos Materiais e Química. É possível inferir desses dados um impacto interdisciplinar da nossa revista de ensino de Física.

\subsection{Web of Science}

A RBEF começou a ser indexada (parcialmente) na WoS em 2007, fazendo parte de sua chamada Coleção Principal até 2013, quando continuou a ser acessível pela plataforma, atualmente gerida pela Clarivate, através da incorporação do Scielo Index. Com isso é possível acessar - pela opção de busca em todas as bases de dados os artigos da RBEF desde 2002, fornecendo talvez um panorama mais completo do que através da base Scopus. A importância de analisar as duas bases é a possível detecção de diferenças de impacto em função da cobertura diferente de revistas. O número de revistas indexadas varia ano a ano, mas em 2016 a cobertura da WoS era de 13.605 periódicos, enquanto que a Scopus englobava 20.346, com vieses em favor de Ciências Naturais em detrimento de Ciências Sociais e Humanas nas duas bases[4]. Essas diferenças de cobertura, no entanto, não modificam as tendências de impacto observadas nas duas bases no caso da RBEF.

A abrangência de indexação da WoS, pela inclusão do Scielo Index, resulta em um conjunto de 1811 documentos publicados na RBEF até a data da coleta dessas dados (25/7/2018), que contabilizam 1502 citações em documentos indexados em todas as bases indexadas nesse portal. A evolução temporal dessas citações é apresentada na Figura 6, indicando também uma clara tendência crescente, apesar das oscilações devidas provavelmente às mudanças na indexação já mencionadas.

Usando as ferramentas de análise de dados disponíveis pela plataforma, encontramos distribuições similares às Figuras 4 e 5 quanto à origem dos artigos citantes de instituições estrangeiras e a distribuição por áreas do conhecimento consideradas pela WoS, Figuras 7 e 8, respectivamente.

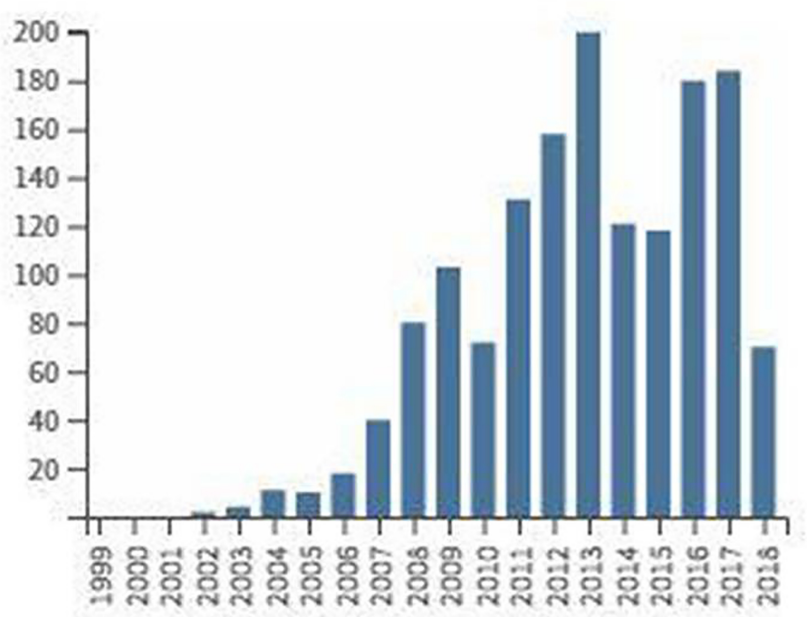

Figura 6: Histograma de citações a documentos publicados na RBEF em documentos indexados na WoS (Figura gerada pela Clarivate, imagem de tela).

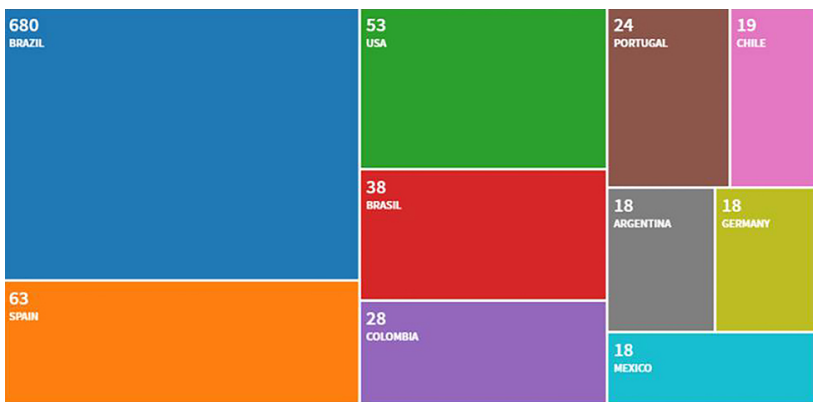

Figura 7: Histograma indicando o número de artigos (por países) que citam documentos publicados na RBEF (Fonte: WoS, imagem de tela).

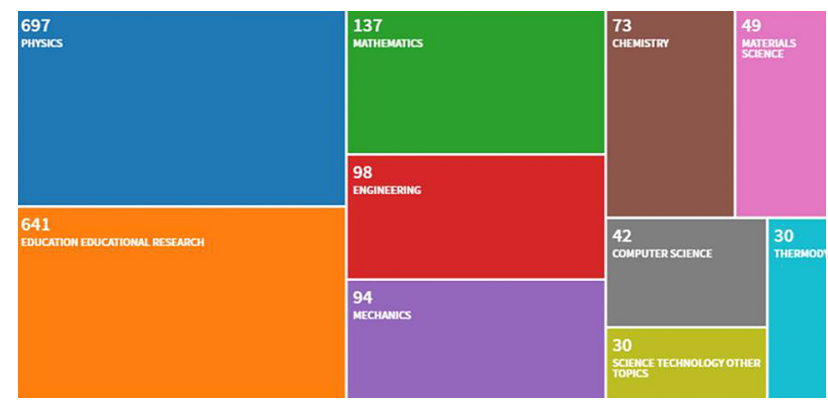

Figura 8: Distribuição dos documentos citantes da RBEF por áreas de conhecimento, segundo a base WoS. (imagem de tela).

As diferenças na cobertura (revistas indexadas) de cada uma das bases revelam-se tanto no número de citações, quanto no ranking dos artigos mais citados, sendo que existem coincidências nessas listagens. A seguir é apresentada a lista dos 10 artigos da RBEF mais citados pela base Scopus, Figura 9.

É importante lembrar novamente que a importância de uma revista não pode ser medida apenas pelas citações que seus artigos recebem em artigos indexados nessa ou naquela base de dados. Esses números indicam 


\begin{tabular}{|c|c|c|c|c|c|c|c|c|c|c|c|}
\hline & Documents & Citations & $<2014$ & 2014 & 2015 & 2016 & 2017 & 2018 & Subtotal & $>2018$ & Total \\
\hline & & Total & 313 & 99 & 121 & 141 & 145 & 135 & 641 & 0 & 954 \\
\hline$\square 1$ & Exact solution for the nonlinear pendulum & 2007 & 19 & 2 & 2 & 2 & 7 & 3 & 16 & & 35 \\
\hline$\square 2$ & [Physics with Arduino for beginners, Fisica com Arduino para... & 2011 & 2 & 1 & 6 & 5 & 3 & 3 & 18 & & 20 \\
\hline$\square 3$ & Fractional order calculus: Historical apologia, basic concep... & 2011 & 2 & 1 & 4 & 3 & 4 & 2 & 14 & & 16 \\
\hline$\square 4$ & Simple measurement of surface free energy using a web cam & 2012 & & & 1 & 2 & 3 & 7 & 13 & & 13 \\
\hline$\square s$ & [The Arduino bosrd: A low cost option for physics experiment... & 2011 & 2 & 1 & 4 & 3 & 1 & 2 & 11 & & 13 \\
\hline$\square 6$ & Acceleration measurements using smartphone sensors: Dealing ... & 2015 & & & 1 & 5 & 3 & 2 & 11 & & 11 \\
\hline$\square 7$ & Ergodic hypothesis in dassical statistical mechanics & 2007 & 6 & 2 & 1 & & 1 & & 4 & & 10 \\
\hline$\square 8$ & [Lorentz symmetry violation, Violação da simetria da Lorentz... & 2007 & 6 & 1 & & & 2 & & 3 & & 9 \\
\hline$\square 9$ & [TiO<in $52</$ int $s$ dye sensitized solar cells, Células solares... & 2006 & 2 & 1 & & 1 & 1 & 4 & 7 & & 9 \\
\hline$\square 10$ & [Bound states in a double delta potential via laplace transf... & 2012 & 2 & 4 & 1 & 1 & & & 6 & & 8 \\
\hline
\end{tabular}

Figura 9: Imagem da página de análise de resultados com alista dos 10 artigos mais citados da RBEF. (Fonte: Scopus, imagem de tela).

apenas uma parte do uso do conhecimento científico publicado. Existem outros usos, em particular no que se refere aos objetivos de um periódico como a RBEF. Seus artigos tem impacto devido ao uso prático no ensino, formação continuada de professores e disseminação de conhecimento com a finalidade de letramento científico da sociedade brasileira. O impacto do uso no ensino e formação de professores pode ser identificado por citações em documentos não indexados, como, por exemplo, em TCCs, dissertações e teses e artigos em revistas não incluídas em nenhuma das bases consideradas até agora. Uma percepção desse impacto pode ser obtida pela comparação entre as citações recebidas pelos artigos listados na Figura 9 e a citações recebidas pelos mesmos artigos, mas capturadas pelo Google Citations. A vantagem do Google Citations é exatamente sua abrangência, embora suas ferramentas de busca sejam ainda limitadas e ainda apresentam imprecisões [2]. Apesar das desvantagens, sua principal vantagem - substancial eliminação de vieses de cobertura - faz com que passe a ser usada como ferramenta de avaliação no lugar da WoS ou Scopus [5].

De um modo geral, o número de citações no Google (busca mais abrangente) é consideravelmente maior, com exceção do último artigo na Tabela 1, que só possui, provavelmente, citações em artigos de periódicos científicos, cuja captura nem sempre é total. Por outro lado, um dos artigos na lista dos 10 mais citados pela WoS (15 citações), "Possibilidades e Limitações das Simulações Computacionais no Ensino da Física", pelo Google Acadêmico são encontradas 263 citações.

\section{Impacto pela medida de acessos}

O impacto e uso dos artigos publicados na RBEF só pode ter uma apreciação mais completa, dadas as características e função do periódico, pelo número de acessos aos artigos e não apenas pelas citações. Essa medida é possível graças ao Scielo Analytics, que contabiliza os acessos de 363 revistas da base. A RBEF ocupa a $85^{\text {a }}$ posição com um total de 3.025.182 acessos, segundo coleta em início de julho de 2018 e referente ao período de 36 meses, de junho de 2015 a maio de $2018^{3}$ Esse número pode oscilar, pois no computo de 36 meses podem sucessivamente ser incluídos(excluídos) meses de

\footnotetext{
${ }^{3} \mathrm{O}$ número total desde 2012 é de 5.188 .587 , sendo 1.789 .549 em pdf.
}

Tabela 1: Comparação entre as citações de artigos publicados na RBEF obtidos na SCOPUS e no Google Citations.

\begin{tabular}{lcc}
\hline Artigo & Citações Scopus & Google citations \\
\hline Exact solution for the nonlinear pendulum & 35 & 77 \\
Physics with Arduino for beginers & 20 & 88 \\
Fractional order calculus: historical apologia, basic concepts... & 16 & 30 \\
Simple measurement of the free energy using a web cam & 13 & 23 \\
The Arduino board: a low cost option for physics & 13 & 18 \\
Acceleration measurements using smatphones sensors & 11 & 23 \\
Ergodic hypothesis in classical statistical mechanics & 10 & 29 \\
Violação da simetria de Lorentz & 9 & 52 \\
Células solares de TiO2 sensibilizado por corante & 9 & 54 \\
Bound states in double delta via Laplace transform & 8 & 2 \\
Total de citações & 144 & 396 \\
\hline
\end{tabular}




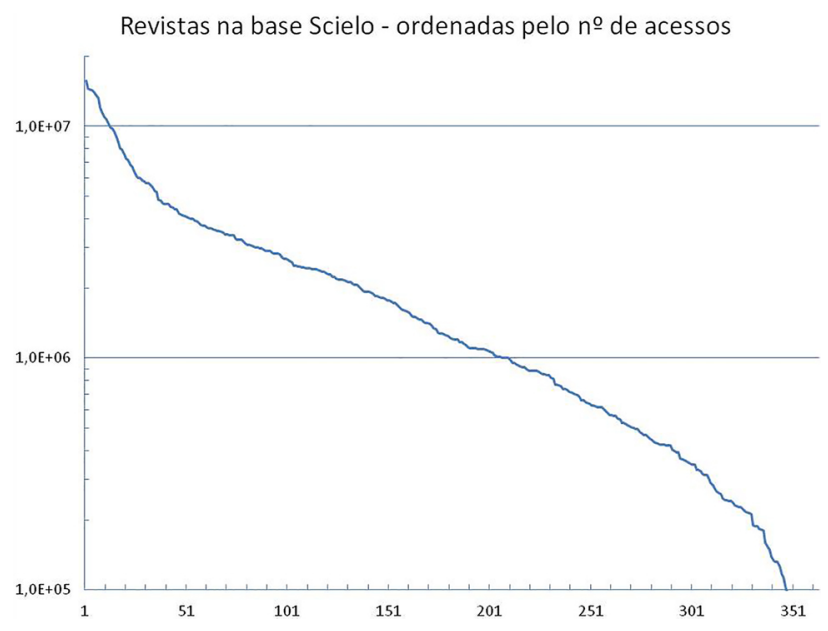

Figura 10: Acessos totais para as 350 revistas da base Scielo mais acessadas (coleta em julho de 2018).

maior(menor) acesso. A representação gráfica ordenada das revistas encontra-se (cortando a escala) na Figura 10. É importante lembrar que é um conjunto de revistas com diferentes temas, públicos, volume de publicação, com preponderância na área de Saúde, incluindo Psicologia, áreas que correspondem a um total de 41 revistas entre as 84 que se encontram acima da RBEF no ranking. Assim, temerário tentar extrair alguma informação adicional do gráfico, incluído a título de ilustração, mas que revela a robustez do uso da base Scielo como fonte de informação científica. Importante ainda é notar que a RBEF é a primeira revista em acessos dentre as revistas que explicitamente colocam ensino em seu escopo e a quinta no ranking entre as que se dedicam (pelo menos parcialmente) à educação de um modo geral.

A ferramenta de análise da Scielo permite obter os acessos mensais da revista, como ilustrado na Figura 11. O indicador talvez mais importante seja o acesso a $\mathrm{pd} \mathbb{f}^{4}$ que indica um acesso a todo artigo (não só o abstract - curva laranja) com intenção de arquivá-lo para uso. O indicador certamente não é uma garantia de que o artigo será usado de alguma forma, como na preparação de uma aula ou experimento, por exemplo, mas é o indicador possível de impacto para além das citações. Observa-se que, excluindo as oscilações (quedas durante os períodos de recessos escolares), a tendência é de aumento no número de acessos. Deve ser destacado que somando os acessos HTML e pdf, a RBEF superou a barreira de 100 mil mensais em maio de 2018 .

A ferramenta de análise também provê a lista dos 100 artigos mais acessados de cada revista e a lista para a RBEF é bastante interessant 5 O topo é ocupado por um artigo (em espanhol) acessado 34.444 vezes (22.629 em pdf). O líder de citações pela Scopus na Tabela 1 (em inglês) acima foi acessado, até agora, 15.514 vezes (5.594 em pdf), sendo o $9^{\circ}$ no ranking de acessos. O artigo em

4 Que corresponde a um total de 1.232 .610 dos 3 milhões no total. 5 https://analytics.scielo.org/w/accesses/list/articles

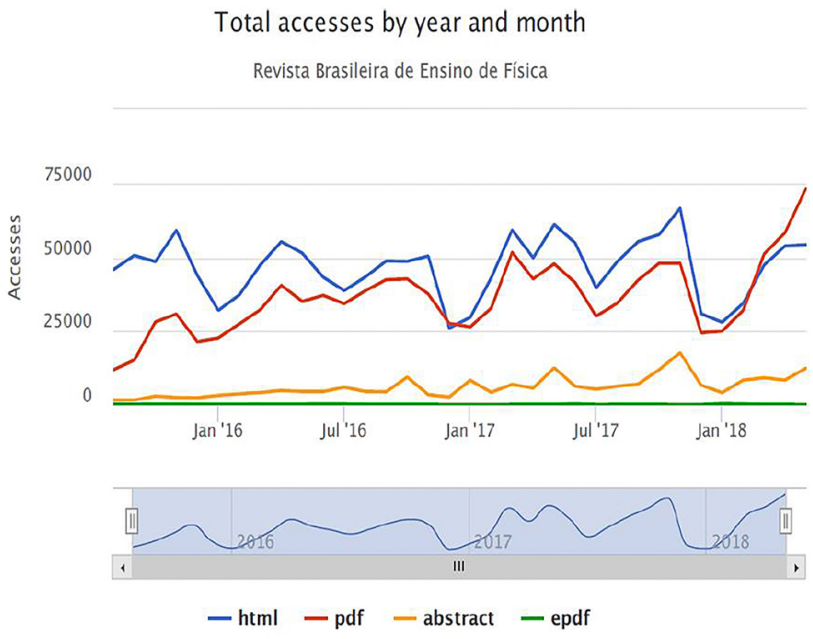

Figura 11: Acessos mensais à RBEF (Fonte: Scielo Analytics, imagem de tela, julho de 2018).

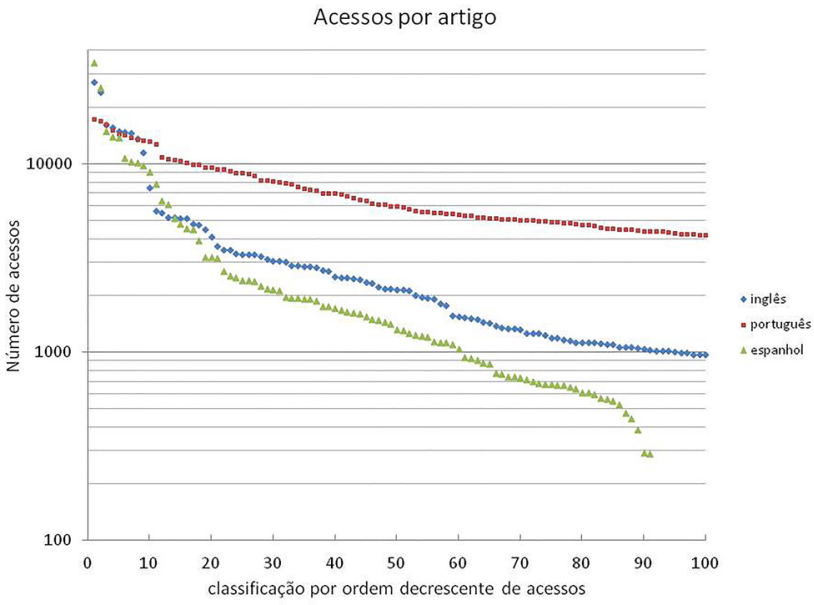

Figura 12: Dados de número de acessos totais dos artigos mais acessados (Fonte: Scielo Analytics, coleta em julho de 2018).

português mais acessado teve mais de 17 mil acessos no total, sendo 12 mil em pdf. As distribuições dos artigos mais acessados por língua - português, espanhol e inglês - estão representadas na Figura 12.

$\mathrm{O}$ acesso aos artigos em português é predominante e apenas um pequeno conjunto de artigos em inglês ou espanhol está entre os mais acessados. Observa-se também na Figura 12 que foram publicados menos do que 100 artigos em espanhol desde 2001, dado que pode estar associado a dois fatores: (i) tamanho menor das comunidades acadêmicas ligadas à temática da RBEF nos países da América Latina e/ou (ii) necessidade de maior divulgação do periódico nessas mesmas comunidades. Outro aspecto importante revelado na Figura 12 é a suavidade da distribuição de número de acessos para artigos em português, ou seja, os indicadores de uso da revista não estão concentrados em um número pequeno de artigos "outli- 


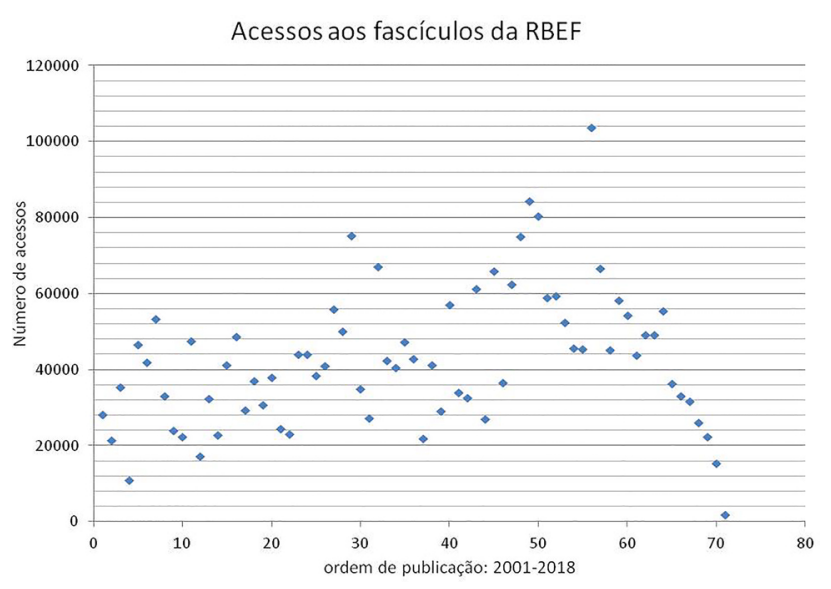

Figura 13: Acessos aos fascículos da RBEF indexados na base Scielo 2001-2018. (Fonte: Scielo Analytics).

ers". Os 291 artigos representados na Figura 12 totalizam 1.370 .744 acessos, $45 \%$ do total para o periódicd 6

$\mathrm{Na}$ discussão sobre métricas complementares o indicador de acessos é tido como promissor na prospecção do uso dos artigos com a ressalva de que acesso não é garantia de que o artigo tenha sido realmente lido ou utilizado, como já mencionado acima [6] No entanto, é um indicador seguro de interesse. Apesar dessa ressalva é razoável considerar a hipótese de que um interesse crescente correlaciona-se com aumento de leitura e uso. A Figura 13 representa os acessos aos fascículos da RBEF, desde o $\mathrm{n}^{\circ} 2$ do volume 23 de 2001 até o último número do volume 40 de 2018, contabilizando, portanto, os acessos aos 70 fascículos editados nesse intervalo de 18 anos.

A inspeção visual da figura sugere o acesso crescente aos fascículos do periódico no tempo com as naturais flutuações de interesse entre as edições. A cauda decrescente e com poucas flutuações para as edições mais recentes é esperada (ocorre o mesmo fenômeno com a evolução temporal do número de citações) e sugere que o acesso aos diferentes números se dá por um intervalo de tempo longo e não apenas logo após seus lançamentos. A correlação de Spearman para os dados da Figura 12, excluindo a cauda mais recente, fornece um coeficiente $\rho=0,57$, sugerindo uma correlação estatisticamente relevante de aumento de acessos às sucessivas edições.

Esses dados deixam claro o impacto expressivo dos documentos publicados pela RBEF para além das citações. De um modo geral, independentemente da base de dados analisada, o impacto da RBEF é crescente, tanto em citações, quanto em acessos, nacional e internacionalmente. É possível aprofundar as análises quanto a língua, origem dos autores, impacto de autocitações, mas os dados apresentados parecem ser suficientes para atestar a importância da RBEF dentro de sua missão declarada.

\footnotetext{
6 A ferramenta do Scielo não permite coletar os acessos de todos os artigos para verificar o comportamento para o conjunto de artigos menos acessados.
}

\section{Referências}

[1] M.H. MacRoberts e B.R. MacRoberts, Journal of the Association for Information Science and Technology 61, 1 (2010).

[2] G Halevi H. Moed e J. Bar-Ilan, Journal of Informetrics 11, 823 (2017).

[3] FC. Gouveia, Liinc em Revista 9, 214 (2013).

[4] P Mongeon e A Paul-Hus, Scientometrics 106, 231 (2016).

[5] P. Jarvey, A. Usher e L. McElroy, Making Research Count: Analyzing Canadian Academic Publishing Cultures (Toronto Higher Education Strategy Associates, 2012).

[6] G Baynes, Insights 25, 311 (2012). 